\title{
PERANCANGAN MESIN 3D PRINTER \\ DENGAN METODE REVERSE ENGINEERING \\ (Studi Kasus di Laboratorium Mekatronika dan Robotics Universitas Tarumanagara)
}

\author{
Frans Jusuf Daywin, Didi Widya Utama, Wilson Kosasih, Kevin William \\ Program Studi Teknik Industri Jurusan Teknologi Industri \\ Fakultas Teknik Universitas Tarumanagara \\ e-mail: fransjusuf42@gmail.com
}

\begin{abstract}
ABSTRAK
Laboratorium Mekatronika dan laboratorium Robotics di Universitas Tarumanagara merupakan laboratorium untuk mempelajari ilmu mekanika, elektronika, dan informatika. Dalam proses produksinya, Laboratorium Mekatronika dan Robotics sangat memperhatikan proses pembuatan robot yang dianalisis mulai dari proses pembuatan rangka dan komponen robot hingga proses pemasangan rangkaian elektronik dan penerapan program pada robot. Reverse engineering merupakan proses analisis produk yang sudah ada sebagai acuan untuk merancang produk yang sejenis dengan memperkecil dan meningkatkan keunggulan produk. Kegiatan Reverse Engineering (RE) dilakukan dengan cara Diassembly 3D printer lama, Assembly 3D printer lama, Benchmarking, Design 3D printer baru, dan terakhir adalah protyping. Reverse engineering dilakukan pada produk 3D printer Grabber i3. Untuk $3 D$ printer baru ini dilakukan inovasi pada material produk, yaitu akrilik, power supply $12 \mathrm{~V} 30 \mathrm{~A}$, motor driver A4988, extruder bowden MK8, dan menambah fitur baru yaitu heatbed.
\end{abstract}

Kata kunci: 3D printer, Produktivitas, Metode Rekayasa Desain, Rekayasa Balik.

ABSTRACT

Mechatronics and Robotics laboratory at Tarumanagara University is a teaching laboratory to study the science of mechanics, electronics, and informatics. In the production process, Mechatronics and Robotics Laboratory are very concerned about the process of making robots that are analyzed from the process of making the framework and robot components to the process of installation of electronic circuits and the application of the program on the robot. This research will be designed and made a machine $3 D$ printer to assist workers in the process of making robot components so as to increase the level of productivity of the work of making robot components. Reverse engineering is an existing product analysis process as a reference for designing similar products by minimizing and increasing product superiority. Reverse Engineering (RE) activities are done by old diassembly $3 D$ printers, old assembly $3 D$ printers, Benchmarking, Design 3D new printers, and the last is protyping. Reverse engineering is done on $3 D$ grabber 3 printer product. For this new $3 D$ printer innovation on product material, acrylic, $12 \mathrm{~V} 30 \mathrm{~A}$ power supply, A4988 motor driver, MK8 bowden extruder, and add new feature that is heatbed.

Keywords:3D printer, Productivity, Engineering Design Method, Reverse Engineering.

\section{PENDAHULUAN}

Kemajuan ilmu pengetahuan dan teknologi di industri saat ini berkembang dengan cepat terutama di bidang otomasih industri. Perkembangan ini dapat dilihat dengan jelas di perindustrian Indonesia, mulai dari yang awalnya banyak pekerjaan menggunakan tenaga manusia, kemudian berkembang berubah menggunakan mesin dan pekerjanya beralih menjadi operator. Tujuan mengotomasih sebuah proses adalah untuk menciptakan kualitas produk yang tinggi, mengurangi biaya produksi, dan mengurangi waktu produksi dalam suatu proses produksi.

Reverse engineering (rekayasa balik) merupakan proses analisis produk yang sudah ada sebagai acuan untuk merancang produk yang sejenis dengan memperkecil dan meningkatkan keunggulan produk [1]. Dengan metode reverse engineering prinsip kinerja dari sebuah alat, objek, atau sistem yang dapat dilakukan dengan menganalisis struktur, fungsi, dan pengoperasiannya. 
Laboratorium Mekatronika dan Robotics merupakan laboratorium untuk mempelajari ilmu mekanika, elektronika, dan informatika. Selain itu, Laboratorium Mekatronika juga berdampingan dengan laboratorium Robotics yang merupakan komunitas untuk mempelajari ilmu-ilmu robotika. Dalam proses produksinya, Laboratorium Robotics sangat memperhatikan proses pembuatan robot yang dianalisis mulai dari proses pembuatan rangka dan komponen robot hingga proses pemasangan rangkaian elektronik dan penerapan program pada robot.

Laboratorium Mekatronika dan Robotics belum memiliki alat bantu dalam proses pembuatan komponen robot sehingga harus membuat komponen robot seperti plat besi secara manual satu per satu yang tidak efisien dalam penggunaan waktu dan tenaga, serta menyebabkan kelelahan fisik dan kecelakaan kerja. Tanpa adanya alat otomasih ini, harus dipotong dan dibengkokkan plat besi tersebut secara manual menggunakan gergaji dan palu bending. Dalam membuat komponen robot, setidaknya memerlukan tingkat kepresisian yang tinggi untuk dapat digunakan pada robot dan jika menggunakan alat otomasih lain seperti mesin CNC (Computer Numerical Control) sangat tidak memungkinkan karena ukuran laboratorium yang tidak cukup besar dan biaya yang dikeluarkan untuk membeli mesin tersebut lebih mahal.

Penelitian ini merancang dan membuat suatu mesin 3D printer guna membantu pekerja dalam proses pembuatan komponen robot sehingga dapat meningkatkan tingkat produktivitas pekerjaan pembuatan komponen robot. Mesin 3D printer yang dirancang ini akan mempermudah pekerja dalam pembuatan komponen robot karena mesin 3D printer ini dapat membuat komponen robot dalam jumlah yang lebih banyak dan presisi jika dibandingkan dengan pembuatan komponen secara manual. Berdasarkan pengamatan yang dilakukan, terdapat berbagai keluhan mengenai tingkat produktivitas dan kepresisian dalam proses tersebut. Hal ini disebabkan karena sering kali terjadi human error sehingga tidak jarang saat pemotongan atau pembuatan lubang meleset dari pola yang sudah ditentukan. Diperlukan adanya mesin 3D printer dalam pembuatan komponen robot agar dapat meningkatkan tingkat produktivitas.

\section{METODE PENELITIAN}

\section{Perencanaan Konsep 3D Printer}

Perencanaan konsep 3D printer menggunakan metode mindmapping yg dipopulerkan oleh Tony Buzan, seorang penulis dan bintang televisi terkenal dari Inggris. Sistem ini jauh lebih efektif dari sistem mencatat linear yang selama ini kita lakukan sejak masihh di bangku sekolah dasar. Mencatat materi runtut ke bawah menggunakan urutan nomor dan angka ternyata tidak sesuai dengan cara bekerja otak kita. Mencatat secara linear berarti menggunakan cara kerja otak kiri, sedangkan mencatat dengan sistem mindmapping adalah cara bekerja otak kanan yang melibatkan kreativitas, imajinasi, visualisasi dan berhubungan langsung dengan otak bawah sadar sehingga mudah untuk diingat. Gambar mindmapping perencanaan konsep 3D printer dapat dilihat pada Gambar 1.

Dari mindmapping dapat dijelaskan bahwa:

1. 3D printer terdapat 3 jenis yaitu: Delta, Core XY, dan Mendel (pada perancangan ini akan dibuat 3D printer jenis mendel)

2. 3D printer memiliki fungsi untuk mencetak model 3D

3. 3D printer pada umumnya memiliki komponen utama: extruder, $x$ axis, y axis, $z$ axis, rangka, micro controler, dan sistem penggerak

4. Perancangan 3D printer baru ini akan dibuat menggunakan metode reverse engineering dengan produk grabber i3, dan untuk pemilihan konsep digunakan metode rekayasa desain/VDI 2221

5. 3D printer dapat mencetak bahan PLA, ABS, Nylon, dan Hips 
6. Kekurangan 3D printer grabber i3 yang ada dipasaran masihh memiliki kekurangan diantaranya: rangka mudah patah; displai kecil dan kurang informatif; saat pencetakkan 3D model mudah copot.

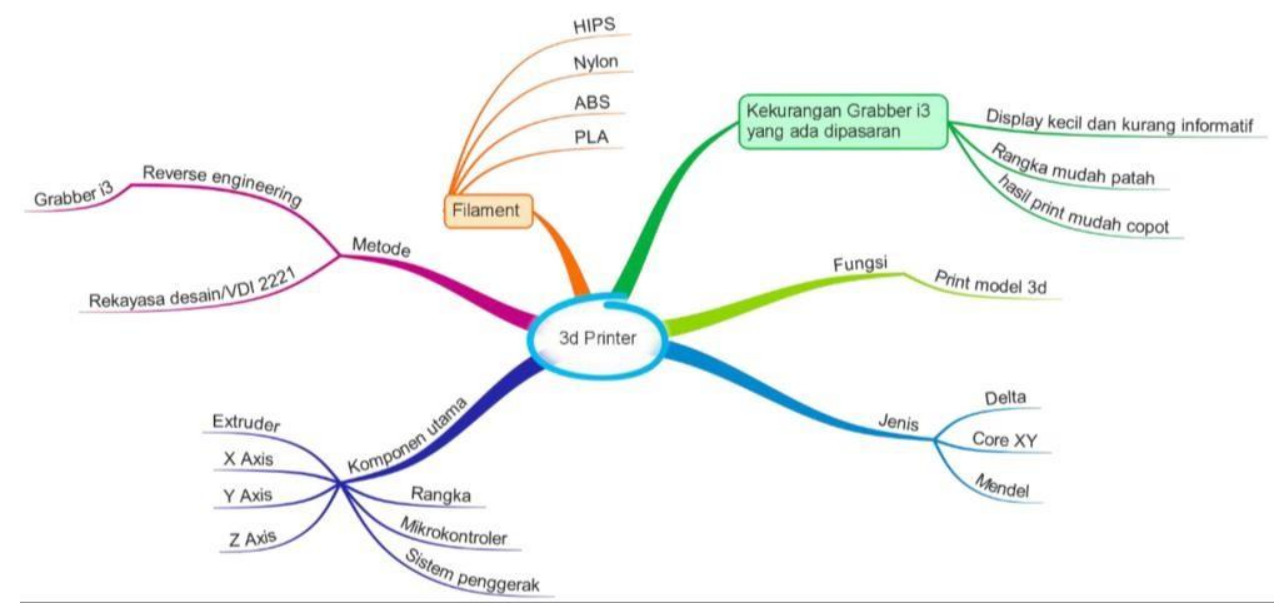

Gambar 1. Mindmapping Perencanaan Konsep 3D Printer

Metode Rekayasa Desain (VDI 2221)[6]

Perancangan dengan menggunakan metode Rekayasa Desain atau VDI 2221 (Verein Deutcher Ingenieure) merupakan salah satu metode untuk menyelesaikan permasalahan dan mengoptimalkan penggunaan material, teknologi dan keadaan ekonomi. Ide dan pengetahuan merupakan sumber dasar dari perancangan produk guna memenuhi permintaan konsumen dan demi keuntungan semua pihak tentunya.

Tabel 1. Daftar Spesifikasi Awal

\begin{tabular}{ccc}
\hline Parameter & Spesifikasi & Demand (D)/ Wish \\
& Dimensi Perancangan & $\mathrm{W}$ \\
Geometri & Panjang & $\mathrm{W}$ \\
& Lebar & $\mathrm{W}$ \\
& Tinggi & $\mathrm{W}$ \\
Gaya & Titik berat yang tepat & $\mathrm{D}$ \\
& Mempergunakan tangan manusia & $\mathrm{D}$ \\
Energi & Bentuk rancangan hemat material & $\mathrm{D}$ \\
& Energi yang berasal dari listrik & $\mathrm{W}$ \\
Material & Efisiensi energi tinggi & $\mathrm{W}$ \\
& Material mudah didapat & $\mathrm{D}$ \\
Perakitan & Komponen tidak mudah rusak & $\mathrm{W}$ \\
Biaya produksi & Material tahan lama & $\mathrm{W}$ \\
& Mudah untuk dibongkar pasang & $\mathrm{W}$ \\
& Biaya pembuatan terjangkau & $\mathrm{D}$ \\
\hline
\end{tabular}

Setelah menentukan spesifikasi awal (Tabel 1), prinsip solusi sub fungsi perlu dibuat untuk menyeleksi komponen yang akan digunakan pada perancangan mesin 3D printer untuk membuat komponen ROV. Prinsip solusi ini dapat dibuat menjadi beberapa varian dan dianalisis dengan tujuan menghasilkan produk dengan nilai efisien yang tinggi. Setelah membuat daftar spesifikasi awal, prinsip solusi sub fungsi perlu dibuat untuk menyeleksi komponen yang akan digunakan pada perancangan mesin 3D printer proses pembuatan komponen. Prinsip solusi ini dapat dibuat sebanyak yang diinginkan dengan tujuan menghasilkan produk dengan nilai efisien yang tinggi. Setelah prinsip solusi sub fungsi 
dibuat, langkah selanjutnya membuat kombinasi yang mungkin sehingga membentuk sistem yang paling menunjang dalam membentuk beberapa varian. Kombinasi prinsip solusi sub fungsi dapat dilihat pada Tabel 2.

Tabel 2. Prinsip Solusi Sub Fungsi dan Kombinasi Prinsip Solusi Sub Fungsi

\begin{tabular}{|c|c|c|c|c|c|}
\hline No & $\begin{array}{l}\text { Prinsip Solusi } \\
\text { Sub Fungsi }\end{array}$ & Keterangan & 1 & 2 & 3 \\
\hline 1 & Rangka & Dibuat & MDF & Akrilik & batang besi \\
\hline 2 & Micro controller & Beli & Arduino ega & Arduino Uno & \\
\hline 3 & Bentuk Heat Bed & Beli & Bulat & Persegi & \\
\hline 4 & Displai & Beli & $\begin{array}{c}\text { RepRap Discount Full } \\
\text { Graphic }\end{array}$ & $\begin{array}{l}\text { LCD Displai Smart } \\
\text { Controller }\end{array}$ & \\
\hline 5 & Sistem Penggerak & Beli & Timing Belt & Rantai & \\
\hline 6 & Jenis $3 \mathrm{D}$ printer & Dibuat & Mendel & $\rightarrow$ Delta & \\
\hline 7 & Arus Power Supply & Beli & 15 Ampere & 20 Ampere & 30 Ampere \\
\hline 8 & Jumlah kipas & Beli & $1 \mathrm{kjpas}$ & 2 kipas & 3 kipas \\
\hline 9 & Sistem extruder & Beli & Direct extruder & Bowden extruder & \\
\hline 10 & Ukuran nozzle & Beli & $0,2 \mathrm{~mm}$ & $0,3 \mathrm{~m}$ & $0,4 \mathrm{~mm}$ \\
\hline
\end{tabular}

Berdasarkan prinsip-prinsip solusi yang telah dilakukan di atas, didapatkan kombinasi varian sebanyak 5.184 lalu dipilih 3 varian sebagai berikut:

1. V1: $1.2 \sim 2.1 \sim 3.2 \sim 4.1 \sim 5.1 \sim 6.1 \sim 7.3 \sim 8.2 \sim 9.2 \sim 10.3$

2. V2: $1.1 \sim 2.2 \sim 3.2 \sim 4.2 \sim 5.2 \sim 6.1 \sim 7.1 \sim 8.1 \sim 9.1 \sim 10.1$

3. V3: $1.3 \sim 2.1 \sim 3.1 \sim 4.1 \sim 5.1 \sim 6.2 \sim 7.2 \sim 8.3 \sim 9.2 \sim 10.2$

Untuk menentukan varian yang mungkin dilanjutkan dalam proses perancangan ini, harus dilakukan seleksi terhadap varian yang ada. Salah satu cara dalam pemilihan varian dapat dilakukan dengan menggunakan diagram seleksi seperti pada Tabel 3.

Tabel 3. Pemilihan Varian Solusi

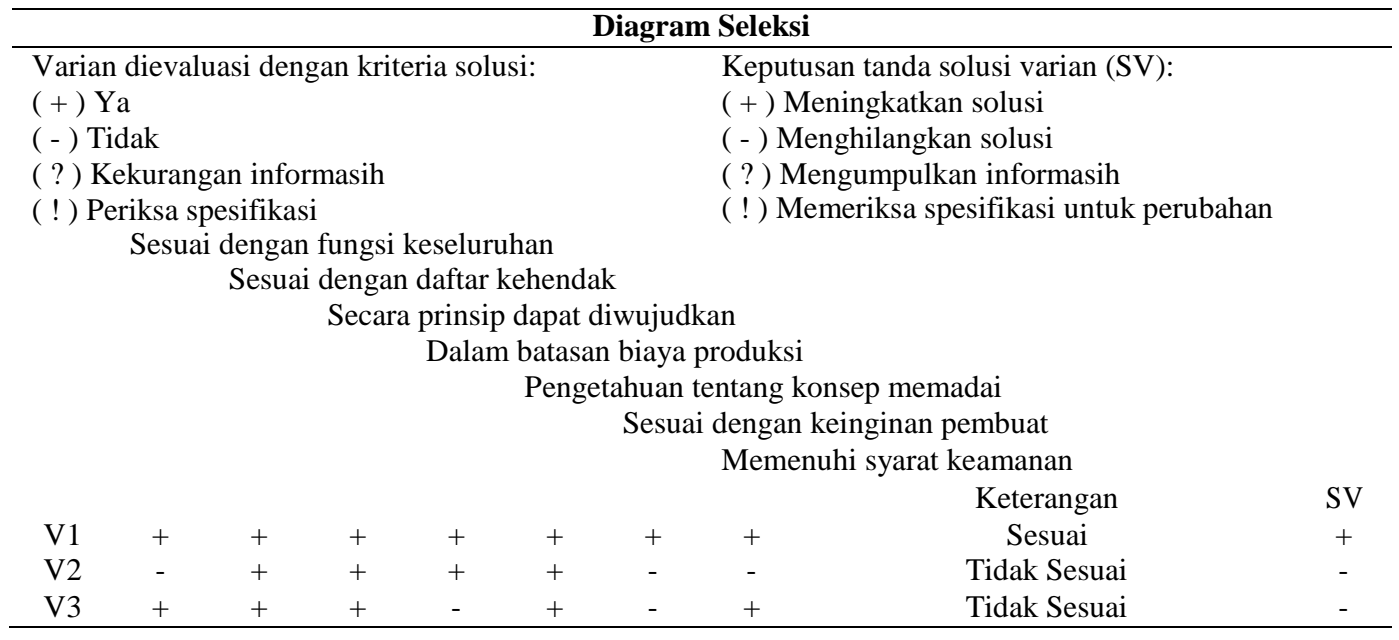

Dari tabel 3 dapat diketahui, varian 1 memenuhi kriteria perancangan. Dengan memperhitungkan sisi biaya produksi dan sesuai fungsi yang dikehendaki untuk mesin 3D printer proses pembuatan komponen ini, maka dipilih varian 1 yang akan dilanjutkan ke proses berikutnya.

Setelah didapatkan prinsip-prinsip solusi sub fungsi, struktur fungsi atau arsitektur produk perlu dibuat untuk mengetahui tata letak yang terbaik untuk membuat sebuah mesin 3D printer dengan mengetahui aliran material, energi, dan sinyal. Struktur fungsi ini dapat dibuat menjadi bentuk perumusan aliran fungsi. 
Setelah terbentuk skema 3D printer selanjutnya adalah pengelompokkan elemenelemen pada skema 3D printer hingga terbentuk menjadi chunk (Gambar 2).

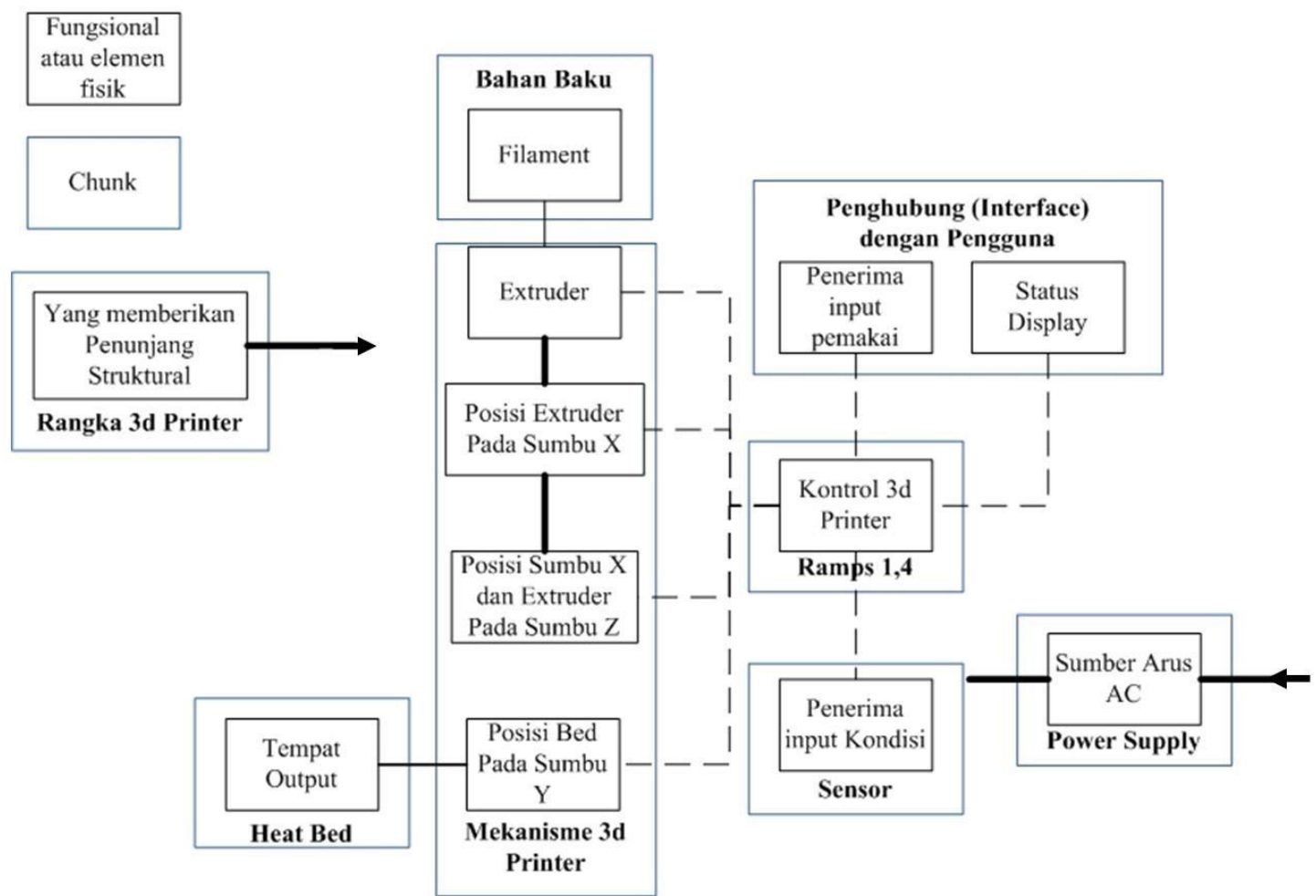

Gambar 2. Skema 3D Printer dan Pengelompokkan Elemen 3D Printer Menjadi Chunk

Varian 1 terdiri dari rangka yang terbuat dari akrilik dan memiliki ketebalan $5 \mathrm{~mm}$, micro controler menggunakan arduino mega, Heat bed ukuran $20 \mathrm{~cm}$ x $20 \mathrm{~cm}$ berbentuk persegi, displai menggunakan reprap discount full graphic yang memiliki tampilan yang lebar, dan sistem penggerak menggunakan timing belt GT2 (Gambar 3).

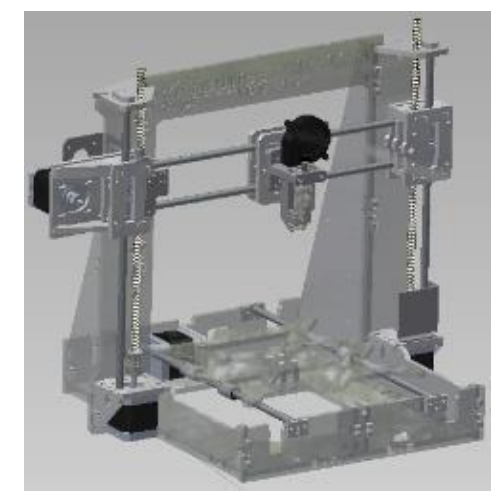

Gambar 3. Rancangan Awal Mesin 3D Printer Terpilih

\section{Kegiatan Reverse Engineering}

Pada Penelitian ini digunakan metode reverse engineering. Pengembangan produk pada penelitian ini menggunakan beberapa prosedur yang dilakukan sebagai berikut: Disassembly; Assembly; Benchmarking; Design mesin 3D printer baru; dan Prototyping.

\section{Disassembly}

Pada tahap ini di lakukan pembongkaran 3D printer lama guna untuk mendapatkan bill of material dan menganalisis fungsi-fungsi dari setiap komponen. Produk yang di bongkar adalah 3D printer grabber i3 (Gambar 4). 


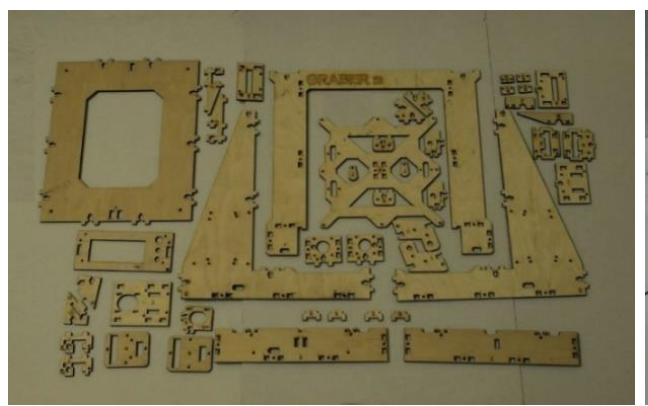

(a)

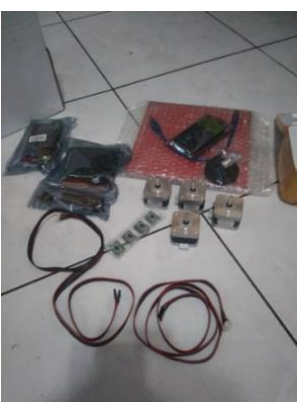

(b)

Gambar 4. Rangka dan Komponen Elektronik 3D Printer Grabber i3 Setelah Dibongkar

Hasil disassembly pada 3D printer grabber i3 didapatkan bahwa dimensi 3D printer adalah $460 \mathrm{~mm} \times 450 \mathrm{~mm} \times 420 \mathrm{~mm}$, dengan jumlah komponen sebanyak 66, dan menggunakan bahan baku kayu MDF (Medium Density Fibreboard). Dan dari hasil disassembly 3D printer tersebut didapatkan data Bill of Material.

Berdasarkan BOM yang telah dijelaskan di atas, dapat diketahui jenis-jenis beserta jumlah dari komponen dan subkomponen yang diperlukan dalam pembuatan 3D printer grabber i3. Berikut adalah part list dari grabber i3 yang dapat dilihat pada Tabel 4.

\section{Assembly}

Pada tahapan ini dilakukan penggabungan kembali komponen-komponen yang sudah dibongkar agar didapat operation process chart mesin 3D printer grabber i3 yang ada dipasaran. Gambar OPC mesin 3D printer grabber i3 dapat dilihat pada Gambar 5.

\section{Benchmarking}

Pada tahap benchmarking ini dilakukan observasi langsung pada mesin 3D printer Grabber i3 yang ada dipasaran lalu membandingkan keunggulan dan kelemahan produk sejenis, kemudian menentukan komponen yang ingin dibenchmark. Penyusunan mesin 3D printer baru digunakan 3 produk yang sudah ada dipasaran, dijelaskan pada Grabber i3 dan Prusa i3.

Tabel 4. Part List Komponen 3D Printer Grabber i3

\begin{tabular}{clccc}
\hline Kode Part & \multicolumn{1}{c}{ Nama Part } & Jumlah & Ukuran/ Bentuk & Make/Buy \\
\hline SA-1 & Rangka & 1 & $400 \mathrm{~mm} \times 350 \mathrm{~mm} \times 370 \mathrm{~mm}$ & Buy \\
SA-2 & X Axis & 1 & $470 \mathrm{~mm} \times 120 \mathrm{~mm} \times 115 \mathrm{~mm}$ & Make \\
SA-3 & Y Axis & 1 & $350 \mathrm{~mm} \times 220 \mathrm{~mm} \times 50 \mathrm{~mm}$ & Make \\
SA-4 & Z Axis & 2 & $42 \mathrm{~mm} \times 42 \mathrm{~mm} \times 365 \mathrm{~mm}$ & Make \\
101 & Power Supply 20 A & 1 & $215 \mathrm{~mm} \times 115 \mathrm{~mm} \times 50 \mathrm{~mm}$ & Buy \\
SA-5 & Mikrokontroler & 1 & $110 \mathrm{~mm} \times 60 \mathrm{~mm} \times 42 \mathrm{~mm}$ & Make \\
201 & Rangka Utama & 1 & $1189 \mathrm{~mm} \times 841 \mathrm{~mm} \times 6 \mathrm{~mm}$ & Buy \\
SSA-1 & Bagian Kiri X Axis & 1 & $100 \mathrm{~mm} \times 82 \mathrm{~mm} \times 80 \mathrm{~mm}$ & Make \\
202 & Smooth Rod & 2 & $\varnothing 8 \mathrm{~mm} \times 400 \mathrm{~mm}$ & Buy \\
SSA-2 & Bagian Tengah X Axis & 1 & $75 \mathrm{~mm} \times 82 \mathrm{~mm} \times 115 \mathrm{~mm}$ & Make \\
SSA-3 & Bagian Kanan X Axis & 1 & $59 \mathrm{~mm} \times 35,6 \mathrm{~mm} \times 80 \mathrm{~mm}$ & Make \\
SSA-4 & Bagian Depan Y Axis & 1 & $20,4 \mathrm{~mm} \times 35.5 \mathrm{~mm} \times 49 \mathrm{~mm}$ & Make \\
SSA-5 & Bagian Tengah Y Axis & 1 & $220 \mathrm{~mm} \times 220 \mathrm{~mm} \times 53 \mathrm{~mm}$ & Make \\
203 & Smooth Rod & 2 & $\varnothing 8 \mathrm{~mm} \times 340 \mathrm{~mm}$ & Buy \\
SSA-6 & BagianBelakang Y Axis & 1 & $71 \mathrm{~mm} \times 55,6 \mathrm{~mm} \times 44 \mathrm{~mm}$ & Make \\
204 & Motor Stepper & 1 & $71 \mathrm{~mm} \times 42 \mathrm{~mm} \times 42 \mathrm{~mm}$ & Buy \\
205 & Linear Bearing LM8UU & 2 & $\varnothing 15 \mathrm{~mm} \times 24 \mathrm{~mm}$ & Buy \\
206 & Smooth Rod & 1 & $\varnothing 8 \mathrm{~mm} \times 317 \mathrm{~mm}$ & Buy \\
207 & Shaft & 1 & $\varnothing 18 \mathrm{~mm} \times 25 \mathrm{~mm}$ & Buy \\
208 & Lead Screw & 1 & $\varnothing 22 \mathrm{~mm} \times 12 \mathrm{~mm}$ & Buy \\
209 & Threaded Rod & 1 & $\varnothing 8 \mathrm{~mm} \times 317 \mathrm{~mm}$ & Buy \\
210 & Limit Switch & 3 & $12 \mathrm{~mm} \times 4 \mathrm{~mm} \times 9 \mathrm{~mm}$ & Buy \\
211 & Ramps 1,4 & 1 & $107 \mathrm{~mm} \times 62 \mathrm{~mm} \times 29 \mathrm{~mm}$ & Buy \\
212 & Motor Driver A4988 & 4 & $20 \mathrm{~mm} \times 15 \mathrm{~mm} \times 10 \mathrm{~mm}$ & Buy \\
\hline
\end{tabular}


Lanjutan Tabel 4. Part List Komponen 3D Printer Grabber i3

\begin{tabular}{clccc}
\hline Kode Part & \multicolumn{1}{c}{ Nama Part } & Jumlah & Ukuran/ Bentuk & Make/Buy \\
\hline 213 & Arduino Mega & 1 & $110 \mathrm{~mm} \times 53 \mathrm{~mm} \times 10 \mathrm{~mm}$ & Buy \\
214 & Thermistor & 2 & $2 \mathrm{~mm} \times 2 \mathrm{~mm} \times 6 \mathrm{~mm}$ & Buy \\
301 & Motor Stepper & 1 & $71 \mathrm{~mm} \times 42 \mathrm{~mm} \times 42 \mathrm{~mm}$ & Buy \\
302 & Pulley GT20 & 1 & $\varnothing 15 \mathrm{~mm} \times 14 \mathrm{~mm}$ & Buy \\
303 & Timing Belt & 1 & $390 \mathrm{~mm} \times 6 \mathrm{~mm} \times 10 \mathrm{~mm}$ & Buy \\
304 & Linear Bearing LM8UU & 3 & $\varnothing 15 \mathrm{~mm} \times 24 \mathrm{~mm}$ & Buy \\
SSSA-1 & Extruder & 1 & $85 \mathrm{~mm} \times 42 \mathrm{~mm} \times 78 \mathrm{~mm}$ & Buy \\
305 & Bearing & 1 & $\varnothing 22 \mathrm{~mm} \times 8 \mathrm{~mm}$ & Buy \\
306 & Bearing & 1 & $\varnothing 22 \mathrm{~mm} \times 8 \mathrm{~mm}$ & Buy \\
307 & Timing Belt & 1 & $286 \mathrm{~mm} \times 6 \mathrm{~mm} \times 10 \mathrm{~mm}$ & Buy \\
308 & Linear Bearing LM8UU & 3 & $\varnothing 15 \mathrm{~mm} \times 24 \mathrm{~mm}$ & Buy \\
309 & Bed & 1 & $220 \mathrm{~mm} \times 220 \mathrm{~mm} \times 3 \mathrm{~mm}$ & Buy \\
310 & Motor Stepper & 1 & $71 \mathrm{~mm} \times 42 \mathrm{~mm} \times 42 \mathrm{~mm}$ & Buy \\
311 & Pulley GT20 & 1 & $\varnothing 15 \mathrm{~mm} \times 14 \mathrm{~mm}$ & Buy \\
401 & Motor Stepper & 1 & $71 \mathrm{~mm} \times 42 \mathrm{~mm} \times 42 \mathrm{~mm}$ & Buy \\
402 & J Head Hot End & 1 & $27,3 \mathrm{~mm} \times 22,3 \mathrm{~mm} \times 81 \mathrm{~mm}$ & Buy \\
403 & MK8 Alumunium Extruder & 1 & $42 \mathrm{~mm} \times 16 \mathrm{~mm} \times 78 \mathrm{~mm}$ & Buy \\
\hline
\end{tabular}

\section{1). Grabber i3}

Benchmarking yang didapat dari Grabber i3 adalah sistem penggerak, extruder, hot end, dan rangka utama, dengan pertimbangan rangka Grabber i3 lebih mudah dimanufaktur dibandingkan dengan 3D printer lainnya yg membutuhkan alat khusus untuk manufaktur rangkanya.

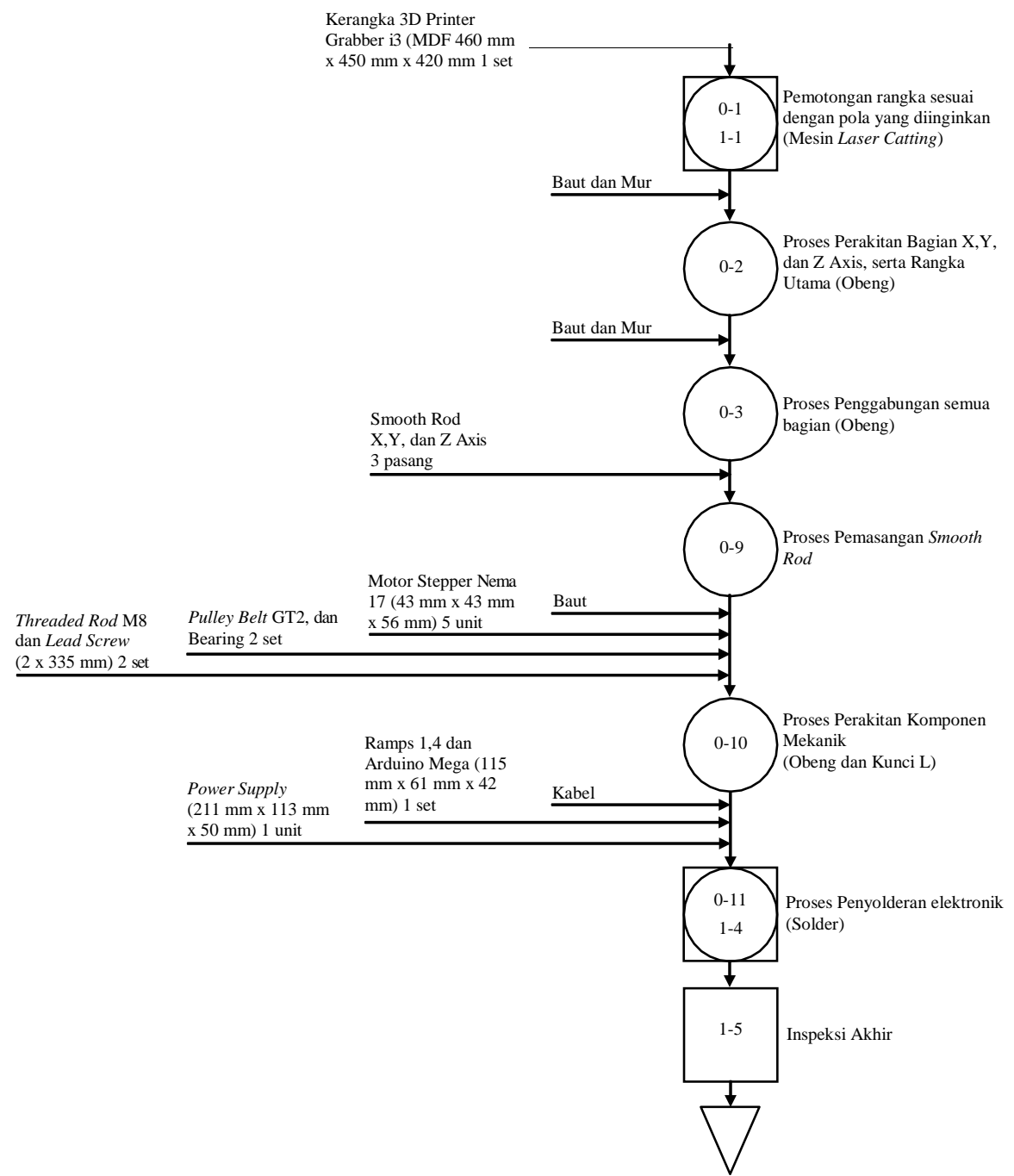

Gambar 5. Operating Process Chart Mesin 3D Printer Grabber i3 


\section{2). Prusa i3}

Benchmarking yang didapat dari prusa i3 adalah motor nema 17, Arduino Mega, Ramps 1,4, pulley dan bearing, Motor driver, material rangka, dan power supply. Benchmarking yang dilakukan dengan Arduino Mega Ramps 1,4, dan motor driver karena lebih mudah diprogram oleh mahasiswa, dan material prusa i3 yg terbuat dari akrilik sehingga lebih kuat dibanding grabber i3 yg terbuat dari MDF (Gambar 6).

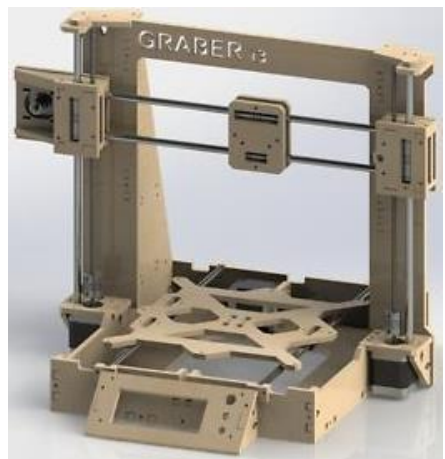

(a)

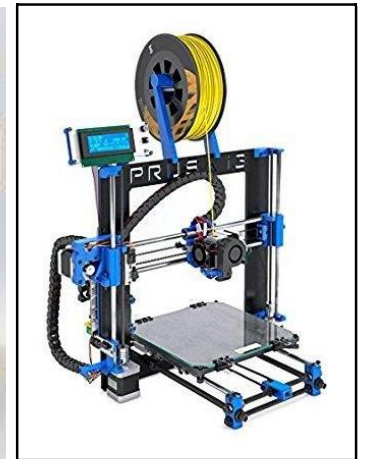

(b)

Gambar 6. Grabber i3 dan Prusa i3

\section{Design Mesin 3D Printer Baru}

Pada tahap ini dirancang sebuah mesin 3D printer dengan cara menggabungkan dan mengembangkan grabber i3 dan prusa i3 dari beberapa tahapan reverse engineering sebelumnya didesign menggunakan Software Autodesk Inventor dalam bentuk 3D model.

Pada mesin 3D printer ini telah dikembangkan mulai dari rangka yang terbuat dari akrilik dengan dimensi $460 \mathrm{~mm}$ x $450 \mathrm{~mm}$ x $420 \mathrm{~mm}$, penambahan heatbed, penggantian displai menjadi reprap discount full graphic, menggunakan power supply $12 \mathrm{~V} 30 \mathrm{~A}$, menggunakan motor nema 17, menggunakan micro controller arduino mega dan RAMPS 1,4.

\section{Prototyping}

Pada tahap ini mesin 3D printer baru yang sudah didesain atau dirancang, dilanjutkan dengan proses manufaktur dimana rangka 3D printer dengan bahan akrilik dan memiliki tebal $5 \mathrm{~mm}$ di manufaktur dengan mesin laser cutting. Setelah rangka selesai dimanufaktur dilanjutkan dengan proses assembly semua komponen 3D printer (Gambar 7).

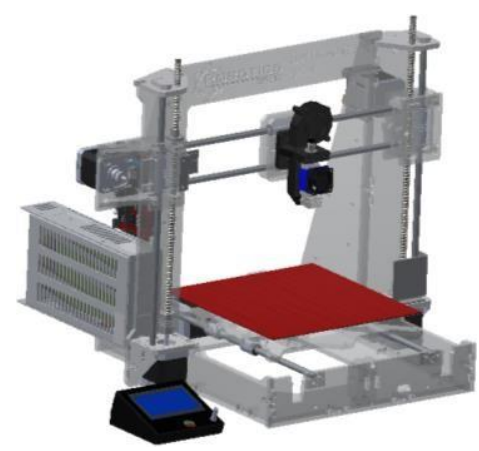

(a) Tampak Depan

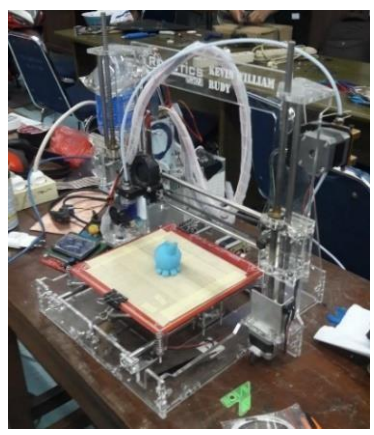

(b) Tampak Samping

Gambar 7. Design Mesin 3D Printer Terbaru

\section{Pemrograman 3D printer}

Pada tahap ini akan dibuat sebuah algoritma pemrograman pada 3D printer yang baru. Pada algoritma ini akan dijelaskan program dibaca oleh mikrokontroler dan meneruskannya hingga 3D model dicetak di atas heatbed. Algoritma pemrograman pada 3D printer yang baru dapat dilihat pada Gambar 8. 



Gambar 8. Algoritma Pemrograman Pada 3D Printer Yang Baru

\section{Spesifikasi Mesin 3D printer Baru.}

Data spesifikasi (Tabel 5) dibutuhkan sebagai acuan dalam manufaktur 3D printer. Dimensi mesin 3D printer terdiri dari panjang $X$ axis sebesar $460 \mathrm{~mm}$, panjang $Y$ axis sebesar $450 \mathrm{~mm}$, panjang $\mathrm{Z}$ axis sebesar $420 \mathrm{~mm}$, ukuran heat bed sebesar 200 x $200 \mathrm{~mm}$, dan menggunakan komponen mesin motor stepper nema 17, mikrokontroler arduino mega dan RAMPS 1,4, motor nema 17, extruder bowden dengan MK8 alumunium, J Head Hot end dengan diameter lubang 0,4 mm, dan motor driver A4988 (Gambar 9).
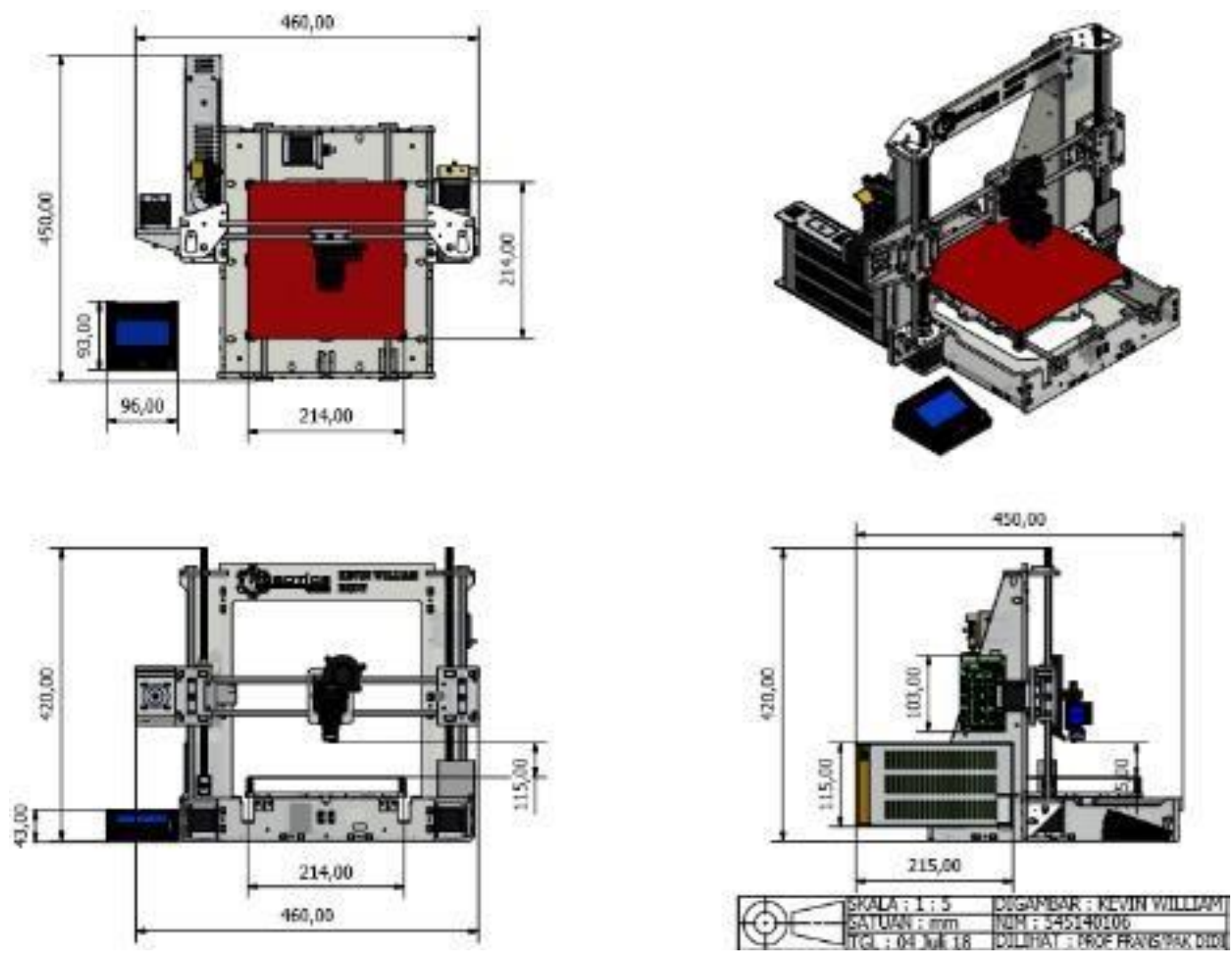

Gambar 9. Spesifikasi Mesin 3D Printer 


\begin{tabular}{cc}
\multicolumn{2}{c}{ Tabel 5. Spesifikasi Mesin $3 D$ Printer } \\
\hline Komponen & Dimensi \\
\hline Panjang X axis & $460 \mathrm{~mm}$ \\
Panjang Y axis & $450 \mathrm{~mm}$ \\
Panjang Z axis & $420 \mathrm{~mm}$ \\
Ukuran yang dapat di cetak & 200 $200 \times 180 \mathrm{~mm}$ \\
\cline { 1 - 2 }
\end{tabular}

Setelah dilakukan pembuatan 3D printer dengan metode reverse engineering maka didapat hasil prototyping mesin 3D printer yang baru, dimana mesin 3D printer yang baru memiliki rangka yang kuat yg terbuat dari akrilik, menambahkan fitur heatbed, dan mengganti displai menjadi reprap discount full graphic yang memiliki displai yg lebih besar dan informatif.

\section{HASIL DAN PERMBAHASAN}

Setelah melakukan proses perancangan mesin 3D printer dengan metode reverse engineering mulai dari tahapan diassembly sampai prototyping. Selanjutnya adalah melakukan proses implementasi mesin 3D printer dengan rancangan baru di laboratorium Robotics UNTAR guna untuk melihat biaya pembuatan 3D printer yang baru.

Kelebihan 3D Printer baru: Rangka mudah dimanufaktur; Kabel dirangkai dengan rapi; Mudah di program; Mudah dioperasikan; Material rangka tidak mudah patah; Dilengkapi dengan heat sehingga tidak; Displai besar dan informatif. Kekurangan 3D Printer baru: Rangka masih mudah goyang; Displai terpisah dengan mesin; Memiliki luas print yang lebih kecil (Gambar 11).

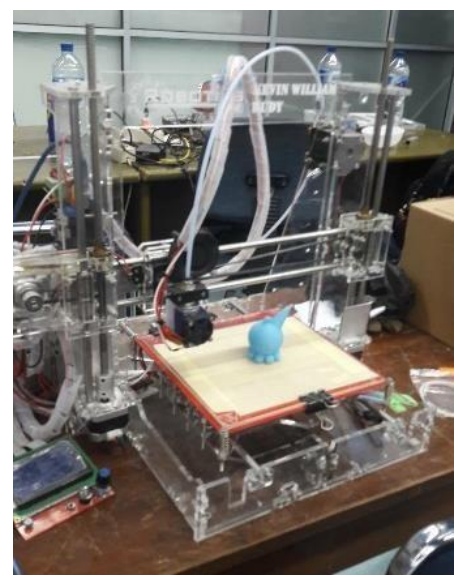

(a)

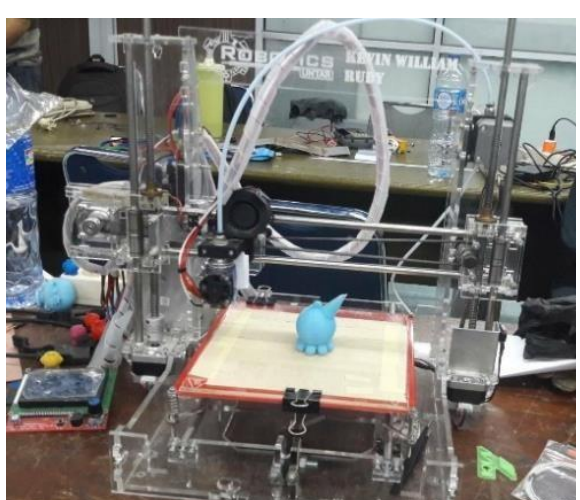

(b)

Gambar 11. Tampak Depan dan Tampak Samping Mesin 3D Printer

\section{KESIMPULAN}

Dari penelitian yang telah dilakukan maka dapat disimpulkan bahwa:

1. Tahap-tahap reverse engineering yang dilakukan untuk mendesain 3D printer baru adalah sebagai berikut:

- Diassembly produk atau pembongkaran 3D printer yang digunakan untuk membuat sebuah 3D printer grabber i3.

- Assembly produk atau penggabungan 3D printer.

- Benchmarking dilakukan untuk membandingkan antara 3D printer yang sudah ada agar dapat di kembangkan dan dilakukan inovasi, agar dapat didesign sebuah 3D printer yang lebih optimal. 
- Design mesin 3D printer baru hasil benchmarking ke 3D CAD model menggunakan software autodesk inventor.

- Prototyping adalah akhir dari proses reverse engineering menghasilkan suatu produk baru yang lebih inovatif yaitu 3D printer baru yang dilengkapi dengan heatbed dan displai reprap discount full graphic.

2. Dari hasil rancangan mesin 3D printer ini didapatkan:

Kelebihan grabber i3: rangka mudah dimanufaktur; kabel dirangkai dengan rapi; mudah di program; mudah dioperasikan dan kekurangan grabber i3: material rangka mudah patah; hasil cetak mudah copot; displai kecil dan kurang informatif.

Kelebihan 3D Printer baru: rangka mudah dimanufaktur; kabel dirangkai dengan rapi; mudah di program; mudah dioperasikan; material rangka tidak mudah patah; dilengkapi dengan heat bed sehingga hasil cetak tidak mudah copot; displai besar dan informatif dan kekurangan 3D Printer baru: rangka masih mudah goyang; displai terpisah dengan mesin; memiliki luas print yang lebih kecil.

\section{DAFTAR PUSTAKA}

[1]. Wibowo, Dwi Basuki, 2006, Memahami Reverse Engineering Melalui Pembongkaran Produk Di Program S-1 Teknik Mesin, Jurnal.Unimus.ac.id, 4 (1):20a-31.

[2]. BPS, 2015, Efisiensi Sistem Produksi Dan Tataniaga Hortikultura, Buku 3, Jakarta. [3]. Eilam, Eldad., 2005, Reversing: Secrets of Reverse Engineering. Indianapolis: Wiley Publishing.

[4]. Otto Kevin N., and Wood Kristin L,1998, Product Design, Techniques in Reverse Engineering ang Product Development, Printed USA.

[5]. Otto Kevin N., and Wood Kristin L, 1998, "A Reverse Engineering and Redesign Methodology", Jurnal Methodology http://alvaresrtech.com/temp/PDP2011 /ems665.ogliari.prof.usfc.br.Restrito/product\%20evolution\%20_\%20\%20reverse\%20 engineerimg20\%and20redesign\%20methodology.pdf. (diunduh 29 Februari 2018, jam 19.25).

[6]. Pahl, G., Beitz, W., Feldhusen, J., and Grote, K.H., 2007, Engineering Design: A Systematic Approach. 3nd ed., London.

[7]. Prasojo, Tuwuh. W, 2016, Perancangan Ulang Mesin Pencacah Rumput Dengan Metode Reverse Engineering, Jurnal Teknik Industri Universitas Muhammadiyah, Surakarta.

[8]. Reprap, 2018, Komponen 3D Printer, http://reprap.org/wiki/Graber_i3 (diakses 24 Februari 2018, jam 20.10).

[9]. Ulrich, Karl T. dan Steven D. Eppinger , 2001, Perancangan Dan Pengembangan Produk. Salemba Teknika, Jakarta.

[10]. Wibowo, Ganang. F, 2016, Perancangan Ulang Produk Pti 1 Menggunakan Metode Reverse Engineering, Jurnal Teknik Industri Universitas Muhammadiyah Surakarta.

[11]. Nugroho, Wahyu Adi, 2008, Perancangan Ulang Alat Pengupas Kacang Tanah Untuk Meminimalkan Waktu Pengupasan, Tugas Akhir Teknik Industri Universitas Muhammadiyah, Surakarta. 